Article

\title{
Comprehensive Performance Evaluation of Electricity Grid Corporations Employing a Novel MCDM Model
}

\author{
Haoran Zhao ${ }^{1,2}$, Huiru Zhao ${ }^{1,2}$ and Sen Guo ${ }^{1,2, *}$ \\ 1 School of Economics and Management, North China Electric Power University, Beijing 102206, China; \\ haoranzhao0118@163.com or 1162106030@ncepu.edu.cn (H.Z.); zhaohuiru@ncepu.edu.cn (H.Z.) \\ 2 Beijing Key Laboratory of New Energy and Low-Carbon Development, North China Electric Power \\ University, Changping, Beijing 102206, China \\ * Correspondence: guosen@ncepu.edu.cn; Tel.: +86-010-6177-3134
}

Received: 2 May 2018; Accepted: 13 June 2018; Published: 22 June 2018

\begin{abstract}
Under the new round reform of electricity market in China, a large amount of electricity sales companies has emerged in some provinces, and the reform of transmission and distribution tariffs is also in progress. Electricity grid corporations are required to update their operational strategies and improve comprehensive performance to adapt to the fierce competition in the electricity market. Considering this, a novel MCDM (multi-criteria decision making) model integrating Fuzzy-Delphi, the best-worst method (BWM), the entropy weight calculation approach, and the VIKOR method is established in this investigation to assess the comprehensive performances of five selected provincial electricity grid corporations. The comprehensive performance assessment indicator system is constructed in accordance with Fuzzy-Delphi approach, composed of 21 significant sub-criteria from the aspects of profitability capacity, development capacity, safety production capacity, electricity supply reliability, outstanding service provision, energy conservation, and environmental protection. The sub-criteria weights are computed by combining subjective weights determined by BWM and objective weights computed by the entropy weight calculation approach. The comprehensive performance evaluation model is established based on VIKOR. As the electricity grid corporation A is superior in profitability capacity (especially in electricity sales amount) and safety production capacity criterion, it is superior over other four electricity grid corporations. The established novel MCDM is practical and rational, which is applicable for electricity grid corporations' comprehensive performance evaluation.
\end{abstract}

Keywords: comprehensive performance evaluation; electricity grid corporations; electricity market reform; BWM; VIKOR

\section{Introduction}

The electricity industry is a significant supporting industry, which has a great influence on national economic growing and energy security [1,2]. As a critical part of the entire power industry chain, power grid corporations undertake the important responsibility of connecting the power generation and power consuming terminals, which plays a primary role in electric grid construction, stable electricity supply, and electric universal service [3-6]. In the period of '12th Five-Year Plan' of China, the total amount of investment on electricity grid construction reached 1.99 trillion Yuan, and the electricity sales amount achieved 21 trillion kWh [7]. Although China ranks the top in several aspects including electricity supply reliability, electricity grid interconnection, electricity generation capacity, and renewable energy installed capacity at present [8-11], electricity grid corporations of China are facing great challenges from social, economic, and environmental perspectives owing to the global economic turbulence, Chinese economic downturn, electricity system reform, and the worsening 
of environmental pollution. Such situations require electricity grid corporations to improve their performance in enhancing profitability capacity and operational efficiency, ensuring safety generation and credibility electricity supply, reducing energy consuming and pollutants emissions, and providing outstanding service.

In 2015, Chinese central government issued a series of documents called 'No.9 Document on Electricity System Reform' which marked the beginning of a new round of electricity system reform [12]. 'No.9 Document' aimed at regaining the commodity attribute of electricity, constructing a competitive power market, and accelerating the orderly and valid development of electricity system through establishing market oriented management and operating mechanisms [13,14]. It also requires electricity grid corporations to manage the transmission, as well as distribution electricity networks, which have the nature of monopoly, and connect orderly with electricity generation corporations and electricity sales corporations, which hold the nature of competition. Based on this, both risks and challenges will be brought to electricity grid corporations considering electricity marketization [6,15]. Furthermore, 'No.9 Document' also proposed that the distribution and transmission tariffs need to be determined on the basis of 'allowable cost added rational profit', which can also promote electricity grid corporations to improve asset management and operating performance.

Due to the reforming of electricity system, electricity sales corporations have emerged in several cities including Beijing, Chongqing, and Shanxi, which broke the monopolistic nature of electricity grid corporations that were treated as the only source to purchase electricity before electricity system reform. Since the electricity grid corporations of China primarily earn their profits via selling electricity, the emergence of electricity sales corporations will bring a negative impact on electricity grid corporations. Hence, on the purpose of ensuring economic earnings and sustainable development, electricity grid corporations should enhance operating management and provide outstanding services. Therefore, under such market contexts, electricity grid corporations should get better acknowledgements of comprehensive performance of their corporations, find weak aspects, and put forward novel management strategies to achieve sustainable development in new policies and fierce competition market environment.

In this research, the comprehensive performances of several electricity grid corporations are evaluated under the context of electricity system reform. Currently, to our best knowledge, literatures on electricity grid corporations' performance evaluation are hard to find. Yan and Tao [16] investigated the operating efficiency of electricity supply enterprises of China using dynamic network slacks based evaluation method. You et al. [7] evaluated the operation performance of electricity grid corporations from economic, social, and environmental perspectives based on an MCDM technology. Currently, the MCDM technique is widely employed in comprehensive evaluation studies, such as evaluating the performance of green suppliers and selecting the optimal one [17-19], prioritizing renewable energy sources [20-22], and wind farm location selection [23-25]. Meanwhile, the MCDM technique utilized in comprehensive evaluation investigations is generally based on the methods including the technology of order preference by similarity to an ideal solution (TOPSIS) [26-29], Vlsekriterijumska Optimizacija I Kompromisno Resenje (VIKOR) [30,31], analytic hierarchy process (AHP) [32], elimination and choice translating reality (ELECTRE) [33], as well as fuzzy theory [34,35].

Considering the ease of calculation and logical calculation procedure, VIKOR method is utilized in this investigation to establish the comprehensive evaluation model. Moreover, the weights of sub-criteria are computed by an innovative MCDM approach, called the BWM [36-38], which is conducted based on pairwise comparisons between various sub-criteria employing numbers 1-9 that is similar to AHP [37]. However, the procedure of BWM is much easier and more consistent than AHP [39-41], which only needs to conduct reference comparing that indicates comparing between all sub-criteria and the worst one and between the best sub-criterion and others [36,38]. BWM has been extensively applied in several researching problems [42-46]. Thus, the established integrated MCDM technology applied to assess the comprehensive performance of electricity grid corporations is based on BWM and VIKOR. The primary devotions of this research contain: 
(1) The comprehensive evaluation index system on assessing electricity grid corporations' comprehensive performance is constructed on the basis of the Fuzzy-Delphi approach, comprehensively considering the views and knowledge of experts.

(2) The sub-criteria weights are identified based on the entropy weighting approach and BWM which, integrates the objective data of each evaluated electricity grid corporation and the preference of each expert.

(3) The comprehensive performance of each selected electricity grid corporation is evaluated based on VIKOR, which can help decision makers get a better acknowledgement of the performance of each aspect and formulate novel market strategies to guarantee the sustainable development of their corporations.

The remaining sections of this investigation are structured as below. Section 2 elaborates basic methodologies of the established novel MCDM model. The comprehensive performance assessment framework is illustrated in Section 3. Section 4 conducts comprehensive performance evaluation in accordance with the established MCDM model step by step. Section 5 discusses the comprehensive performance evaluation results, conducts a comparative analysis, and recommends some policy implications in terms of the comprehensive performance evaluation results. Conclusions are listed in Section 6.

\section{Basic Methodologies of the Established MCDM Model}

\subsection{Fuzzy-Delphi Approach}

The Delphi approach, established by Dalky and Helmer, was utilized to obtain credible opinions among experts and has been extensively employed in decision making [47]. The conventional Delphi approach consumes lots of time and it is difficult to achieve consensus, as it requires experts to provide their feedback and revise their opinions via four rounds consultations [48]. After that, the Fuzzy-Delphi approach was constructed to solve the above demerits integrating conventional Delphi approach and the fuzzy methodology. In the Fuzzy-Delphi approach, experts should provide three-point evaluations utilizing triangular fuzzy numbers (TFNs) [49]. The membership function cannot only demonstrate the opinions of experts, but also take all views into consideration that will not miss any information. In terms of the outstanding performance of Fuzzy-Delphi approach, it has been utilized in various researches in screening evaluation indicators [50]. The procedures of Fuzzy-Delphi approach are elaborated as below.

Step 1: Identifying the top limit and bottom limit of the significance range from 0 to 10 of every original sub-criterion in terms of experts' preference. The greater the number is, the more critical the original sub-criterion is. The top limit demonstrates the positive value, while the bottom limit illustrates the conservative value.

Step 2: Computing the conservative TFN $\left(C_{L}^{i}, C_{M}^{i}, C_{U}^{i}\right)$ and positive TFN $\left(P_{L}^{i}, P_{M}^{i}, P_{U}^{i}\right)$ for every sub-criterion, among which $C_{L}^{i}$ and $P_{L}^{i}$ are the least values of the conservative value and take positive values, $C_{M}^{i}$ and $P_{M}^{i}$ represent the geometric average values of the conservative value and take positive values, as well as $C_{U}^{i}$ and $P_{U}^{i}$, which mean the greatest values of the conservative value and take positive values in terms of experts opinions.

Step 3: Testing on the consensus of experts' views and determining the coherent value $G_{i}$ of $i$ sub-criterion [50,51].

(1) For $C_{U}^{i} \leq P_{L}^{i}$, views on the significance of $i$ sub-criterion are coherent, the coherent value $G_{i}$ is calculated as:

$$
G_{i}=\frac{C_{M}^{i}+P_{M}^{i}}{2}
$$


(2) For $C_{U}^{i}>P_{L}^{i}$, if the grey zone value $Z^{i}=C_{U}^{i}-P_{L}^{i}$ is less than the value $M^{i}=P_{U}^{i}-C_{M^{\prime}}^{i}$, then the coherent value $G_{i}$ is computed as:

$$
G_{i}=\frac{\left[\left(C_{U}^{i} \times P_{M}^{i}\right)-\left(P_{L}^{i} \times C_{M}^{i}\right)\right]}{\left[\left(C_{U}^{i}-C_{M}^{i}\right)+\left(P_{M}^{i}-P_{L}^{i}\right)\right]}
$$

For $C_{U}^{i}>P_{L}^{i}$, if the grey zone value $Z^{i}=C_{U}^{i}-P_{L}^{i}$ is greater than $M^{i}=P_{U}^{i}-C_{M}^{i}$, experts' views are not coherent. The procedure needs to return back to Steps 1 and 2 . The coherent value $G_{i}$ demonstrates the coherent degree obtained by experts in terms of the significance of every indicator. The greater the $G_{i}$ becomes, the more critical the indicator is. The rational significant threshold value for testing the significance of every sub-criterion is determined based on the geometric mean data of top limits and bottom limits of all original sub-criteria, which is applied to identify the critical sub-criteria.

\subsection{The Best-Worst Method}

BWM is a novel MCDM method based of reference comparison, which only needs $2 n-3$ ( $n$ demonstrates the sub-criteria amount) comparisons $(n-2$ comparisons between the best sub-criterion and others, $n-2$ comparisons between others and the worst one, and 1 comparison between the best and the worst ones) [36]. The detailed procedure of BWM is illustrated as below.

Step 1: Considering about the research object, an original sub-criteria system $\left\{S_{1}, S_{2}, \ldots, S_{n}\right\}$ needs to be constructed, which aims at comprehensively reflecting the performances of various alternatives.

Step 2: Determine the best and the worst sub-criteria among the original sub-criteria system. The selection of them only considers the significance of each sub-criterion, but not the value.

Step 3: Compare the significance degree between the best sub-criterion and others via the number in the scope of 1-9. The larger the value is, the more vital the best one over others is. The comparison preference can be represented as:

$$
A_{B}=\left(a_{B 1}, a_{B 2}, \ldots, a_{B n}\right),
$$

where $a_{B i}$ implies the comparison preference of the best one over sub-criterion $i$, and $a_{B B}=1$.

Step 4: Assign the comparison preference value between others and the worst one via the number in the scope of 1-9. The results can be written as:

$$
A_{W}=\left(a_{1 W}, a_{2 W}, \ldots, a_{n W}\right)^{T},
$$

where $a_{i W}$ demonstrates the comparison result between sub-criterion $i$ and the worst one, and $a_{W W}=1$.

Step 5: Compute the weights $\left(w_{1}^{*}, w_{2}^{*}, \ldots, w_{n}^{*}\right)$. To compute the optimal weights of all indicators, we need to minimize the maximum absolute disparity $\left\{\left|w_{B}-a_{B i} w_{i}\right|,\left|w_{i}-a_{i W^{W}} w_{W}\right|\right\}$ of all sub-criteria, which can be written as 37 :

$$
\begin{gathered}
\min \max _{i}\left\{\left|w_{B}-a_{B i} w_{i}\right|,\left|w_{i}-a_{i W} w_{W}\right|\right\} \\
\text { s.t. } \\
\sum_{i} w_{i}=1 \\
w_{i} \geq 0, \text { for all } i .
\end{gathered}
$$


At the aim of simplifying the calculation procedure, Equation (5) can be transferred into a linear form as Equation (6) 37:

$$
\begin{gathered}
\min \xi \\
\text { s.t. } \\
\left|w_{B}-a_{B i} w_{i}\right| \leq \xi, \text { for all } i \\
\left|w_{i}-a_{i W} w_{W}\right| \leq \xi, \text { for all } i \\
\sum_{i} w_{i}=1 \\
w_{i} \geq 0, \text { for all } i .
\end{gathered}
$$

Through solving the linear Equation (6), the optimum weights $\left(w_{1}^{*}, w_{2}^{*}, \ldots, w_{n}^{*}\right)$ can be obtained.

Step 6: Test the comparison consensus. Through solving Equation (6), the value of $\xi$ can be obtained that is employed in comparison consensus examination. The consensus indicator is determined based on various values of $a_{B W}$ in the scope of $1-9$, the values of which are shown in Table 1. The consensus ratio is computed as below:

$$
\text { Consensus ratio }=\frac{\xi^{*}}{\text { Consensus indicator }}
$$

The lower the $\xi^{*}$ is, the lower the consensus ratio is, the more coherent the preferences become.

Table 1. Consensus Indicator (CI).

\begin{tabular}{cccccccccc}
\hline $\boldsymbol{a}_{\boldsymbol{B} W}$ & $\mathbf{1}$ & $\mathbf{2}$ & $\mathbf{3}$ & $\mathbf{4}$ & $\mathbf{5}$ & $\mathbf{6}$ & $\mathbf{7}$ & $\mathbf{8}$ & $\mathbf{9}$ \\
\hline $\mathrm{CI}\left(\max \zeta^{*}\right)$ & 0.00 & 0.44 & 1.00 & 1.63 & 2.30 & 3.00 & 3.73 & 4.47 & 5.23 \\
\hline
\end{tabular}

\subsection{Entropy Weight Calculation Method}

Entropy weight calculation approach determines the weights of objective sub-criteria based on actual data [52]. The process of entropy weight calculation approach is introduced as below.

Step 1: Standardizing the evaluated values. The evaluated values of $j$ alternative corresponding to $i$ sub-criterion need to be standardized, and then the normalized value $p_{i j}$ is computed as:

$$
p_{i j}=\frac{x_{i j}}{\sum_{j=1}^{m} x_{i j}}
$$

where $x_{i j}$ represents the evaluated values of $j$ alternative corresponding to $i$ sub-criterion, and $m$ is the amount for each alternative.

Step 2: Computing entropy values. $e_{i}$ is employed to represent the entropy value which can be obtained by:

$$
e_{i}=-k \sum_{j=1}^{m} p_{i j} \ln \left(p_{i j}\right)=-\frac{1}{\ln m} \sum_{j=1}^{m} p_{i j} \ln \left(p_{i j}\right)
$$

Step 3: Calculating the deviation degree. The deviation degree $g_{i}$ of every sub-criterion is calculated as:

$$
g_{i}=1-e_{i}
$$

Step 4: Calculating the weights of objective sub-criteria. The following equation is utilized to calculate the weights $\lambda_{i}$ of objective sub-criteria:

$$
\lambda_{i}=\frac{g_{i}}{\sum_{i=1}^{n} g_{i}}
$$




\subsection{VIKOR Comprehensive Assessment Model}

VIKOR model was constructed for multi-criteria comprehensive evaluation for complex system. It can make out the compromise rankings and alternatives in accordance with the assessment of 'closeness' to the 'ideal values' [53,54]. The process of VIKOR approach is expressed as below.

Step 1: Standardize the evaluated values of all alternatives. To avoid the impacts of dimension and attribute on assessment, the original values $a_{i j}$ should be standardized. Considering that the index system contains minimum type and maximum type indicators, the standardized values $x_{i j}$ are computed through employing Equations (12) and (13), respectively.

$$
\begin{aligned}
& x_{i j}=\frac{a_{i j} \min _{j}\left(a_{i j}\right)}{\max _{j}\left(a_{i j}\right)-\min _{j}\left(a_{i j}\right)} \\
& x_{i j}=\frac{\max _{j}\left(a_{i j}\right)-a_{i j}}{\max _{j}\left(a_{i j}\right)-\min _{j}\left(a_{i j}\right)}
\end{aligned}
$$

Step 2: Find the negative and positive ideal solutions. $X^{+}$and $X^{-}$are assumed to demonstrate the positive ideal solution and negative one, respectively, which are expressed as:

$$
\left\{\begin{array}{l}
X^{+}=\left(x_{i}^{+}\right)=\left\{\left(\max _{j} x_{i j} \mid i \in I_{1}\right),\left(\min _{j} x_{i j} \mid i \in I_{2}\right)\right\} \\
X^{-}=\left(x_{i}^{-}\right)=\left\{\left(\min _{j} x_{i j} \mid i \in I_{1}\right),\left(\max _{j} x_{i j} \mid i \in I_{2}\right)\right\}
\end{array}\right.
$$

where $I_{1}$ and $I_{2}$ represent the sets of maximum and minimum type indicators, respectively.

Step 3: Obtain the group benefit data $S_{j}$ as well as the individual regret result $R_{j}$ of $j$ alternative based on the following two equations.

$$
\begin{gathered}
S_{j}=\sum_{i=1}^{n} \frac{w_{i}\left(x_{i}^{+}-x_{i j}\right)}{x_{i}^{+}-x_{i}^{-}} \\
R_{j}=\max _{i}\left(\frac{w_{i}\left(x_{i}^{+}-x_{i j}\right)}{x_{i}^{+}-x_{i}^{-}}\right)
\end{gathered}
$$

Step 4: Compute the compromise sorting result $Q_{j}$ of each alternative. $Q_{j}$ is taken as the significant evidence in ranking all alternatives that is computed as:

$$
Q_{j}=\frac{v\left(S_{j}-S^{+}\right)}{S^{-}-S^{+}}+\frac{(1-v)\left(R_{j}-R^{+}\right)}{R^{-}-R^{+}}
$$

where $S^{-}=\max _{j}\left(S_{j}\right), S^{+}=\min _{j}\left(S_{j}\right), R^{-}=\max _{j}\left(R_{j}\right), R^{+}=\min _{j}\left(R_{j}\right), v$ illustrates the weight of the largest group benefit, and generally we set $v=0.5$.

Step 5: Rank all evaluated alternatives by comparing $S_{j}, R_{j}$, and $Q_{j}$. If two conditions below are satisfied, the evaluated alternative with the minimum $Q_{j}$ value is the optimal selection.

$Q\left(A^{(2)}\right)-Q\left(A^{(1)}\right) \geq 1 /(m-1)$

where $Q\left(A^{(1)}\right)$ and $Q\left(A^{(2)}\right)$ demonstrate alternatives ranking the first and second in accordance with $Q_{j}$ values.

(2) $A^{(1)}$ needs to rank the first in terms of $S_{j}$ and $R_{j}$ values.

$A^{(1)}$ will be the optimum selection if above two conditions are satisfied. Moreover, if one of the terms is not qualified, some compromise terms are provided: 
(1) If only the first qualification is met, both $A^{(1)}$ and $A^{(2)}$ are the optimal selection.

(2) If the first term cannot be qualified and only the second one is met, the alternatives that cannot adhere to the first one are the compromise selections.

\section{Comprehensive Evaluation Framework}

The established MCDM model is utilized to comprehensively evaluate the performance of electricity grid corporations based on Fuzzy-Delphi approach, the BWM, entropy weight calculation approach, and VIKOR assessment models. The procedures are elaborated as below.

Step 1: Select the critical sub-criteria to establish the comprehensive assessment index system in accordance with Fuzzy-Delphi. At this phase, experts from related researching areas are chosen as the consulting group. Original sub-criteria are listed and Fuzzy-Delphi is utilized to pick out the most significant sub-criteria, which can synthetically reflect the characteristics of electricity grid corporations in terms of experts' preference.

Step 2: Determine the combination weights based on the results of the BWM and entropy weights calculation approach. We utilized the BWM as a subjective weighting approach, which can reflect the opinions of experts, and the entropy weights calculation approach as the objective weighting approach, which can reflect the actual situation of electricity grid corporations. Through calculating subjective weights and objective weights in accordance with these two methods, the final weights of all sub-criteria are obtained via computing the average values of the two methods results.

Step 3: Comprehensively assess the performance of all selected electricity grid corporations utilizing the VIKOR approach. After standardizing the initial decision matrix and finding the positive and negative ideal values of all sub-criteria, VIKOR approach is utilized to discover the optimum alternative in terms of values of $Q_{j}, S_{j}$, and $R_{j}$.

Figure 1 illustrates the overall framework of the established MCDM model on comprehensively assessing the performance of electricity grid corporations. 


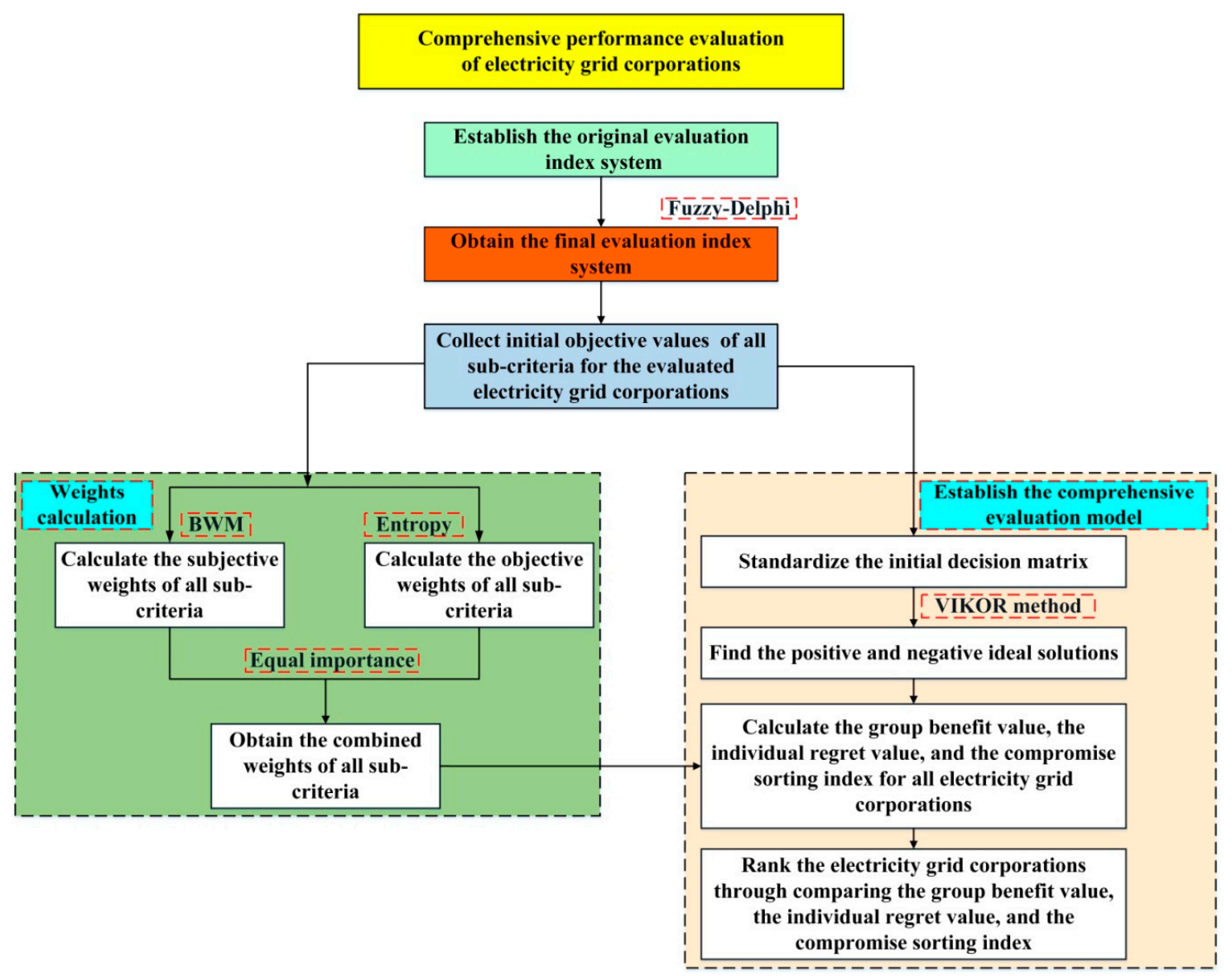

Figure 1. The overall framework of the established MCDM model for comprehensively assessing the performance of electricity grid corporations.

\section{Comprehensive Performance Evaluation Results}

\subsection{Evaluation Index System Establishment}

To make a comprehensive evaluation of electricity grid corporations performance, the assessment index system needs to be established, which contains the most significant sub-criteria and can reflect various characteristics of the evaluated electricity grid corporations. Based on the performance of electricity grid corporations, 40 original sub-criteria were chosen to construct the initial index system from the perspectives of profitability aspect, development capacity, safety production capacity, electricity supply reliability, outstanding service provision, and energy conservation, and environmental protection. To construct the final index system, Fuzzy-Delphi approach was utilized to screen significant sub-criteria in terms of experts' preferences. Five experts were chosen from corresponding researching areas, including scholars researching on electricity grid corporations operation, as well as governors of electricity grid corporations, to be the members of consulting group. For scholars researching on electricity grid corporations operation, they have a better understanding on how to improve the performance of electricity grid enterprises and can identify the indicators which can pose great significance on the performance of electricity grid enterprises. For governors of electricity grid corporations, they decide the developing direction of electricity grid corporations and master the comprehensive operation situation of electricity grid corporations so that they can comprehensively select the indicators reflecting the performance of electricity grid enterprises.

Firstly, five experts needed to provide their preferences on the significance of 40 original sub-criteria, and at this step, the positive and conservative values of every sub-criterion can be identified. After that, the conservative TFN $\left(C_{L}^{i}, C_{M}^{i}, C_{U}^{i}\right)$ and positive TFN $\left(P_{L}^{i}, P_{M}^{i}, P_{U}^{i}\right)$ for 
every sub-criterion were computed. Then the values of $G_{i}$ can be calculated via Formulae (1) and (2) by comparing $C_{U}^{i}$ and $P_{L}^{i}$. Through comparing $G_{i}$ with the critical value (which is 4.66), the significant sub-criteria with $G_{i}$ higher than 4.66 will be selected to make up the final index system. The Fuzzy-Delphi results are illustrated in Table A1, and the final index system was composed of 21 significant sub-criteria from the aspects of profitability capacity, development capacity, safety production capacity, electricity supply reliability, outstanding service provision, and energy conservation, and environmental protection.

As illustrated in Figure 2, all 21 final sub-criteria were quantitative indicators, and 8 of them were minimum type and 13 of them were maximum type sub-criteria.

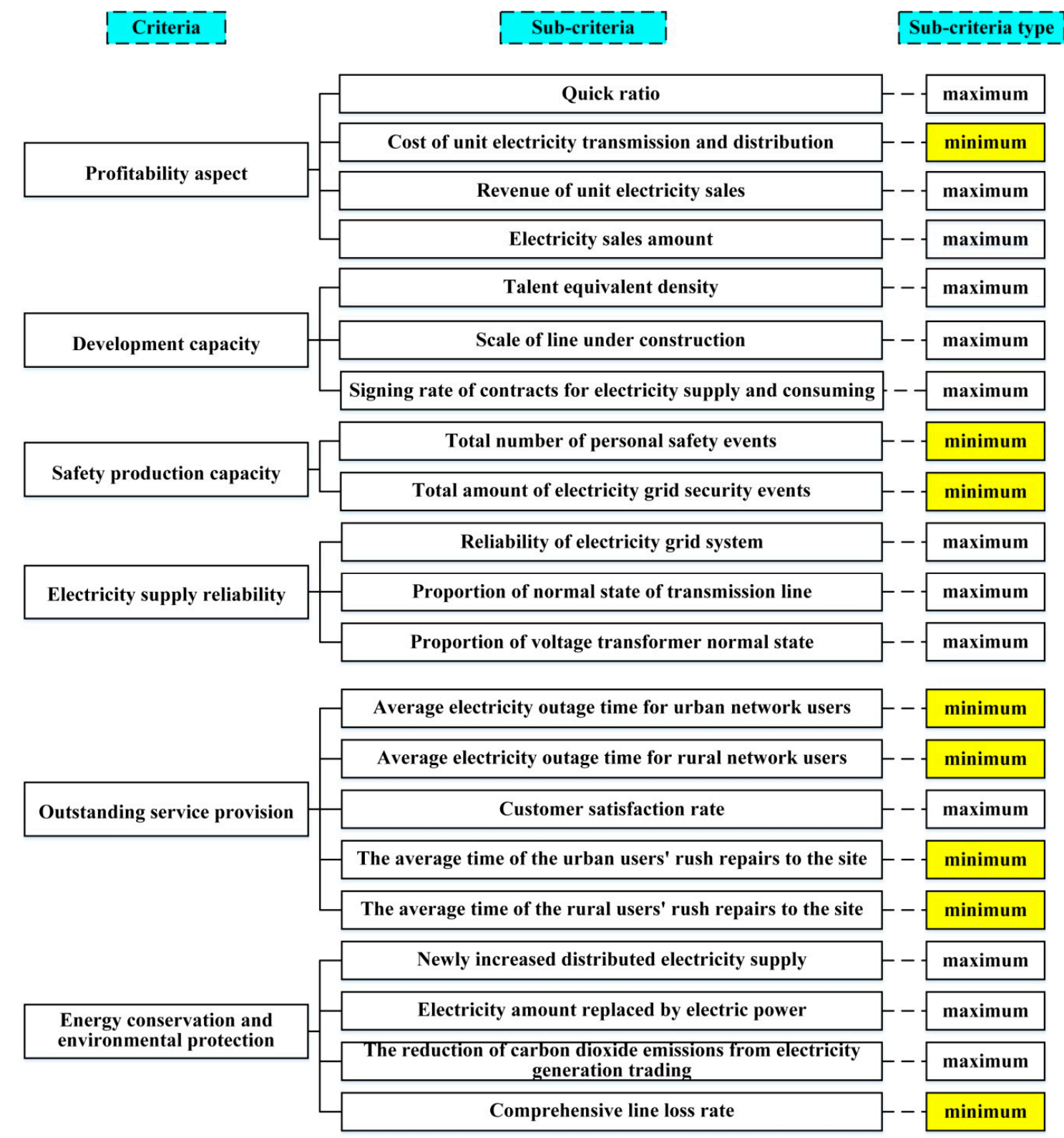

Figure 2. Final index system for comprehensive performance evaluation on electricity grid corporations.

For profitability aspect, the core of electricity grid corporations is to create values, thus the comprehensive performance evaluation on electricity grid corporations should focus on profitability aspect. Considering the experts' preferences, quick ratio, cost of unit electricity transmission and distribution, revenue of unit electricity sales, and electricity sales amount were selected as the 
sub-criteria to reflect features of profitability aspect of electricity grid corporations. For quick ratio, it indicates the proportion of quick assets to current liabilities, which can reflect debt paying ability to guarantee normal operation. We use cost of unit electricity transmission and distribution to reflect the main business cost and revenue of unit electricity sales, as well as electricity sales amount to represent the main business income of electricity grid corporations.

For development capacity, it is defined as a comprehensive indicator reflecting the critical capability input of electricity grid companies to achieve sustainable development and healthy operation. For electricity grid corporations, they need to input labor force and infrastructure, hence considering about experts' views, talent equivalent density, scale of line under construction, and signing rate of contracts for electricity supply and consuming were selected to reflect development capacity. For talent equivalent density, it is a key indicator for the electricity grid companies to assess the proportion of senior personnel in the proportion of their human resources. Scale of line under construction can reflect the infrastructure construction of electricity network. Signing rate of contracts for electricity supply and consuming can reflect the market developing level which can reflect the market share of electricity grid corporations.

Safety production is a vital condition for electricity grid corporations to ensure operational efficiency. Considering about the preferences of experts, total number of personal safety events and total amount of electricity grid security events were selected to reflect safety production capacity of electricity grid companies.

For electricity supply reliability, since electric power is the necessary energy in daily life, reliable electricity supply is also a significant factor to assess the performance of electricity grid companies. Therefore, we selected reliability of electricity grid system, proportion of normal state of transmission line, and proportion of voltage transformer normal state to reflect the state of the network in transmission and distribution process.

For outstanding service provision, with the emergence of electricity selling companies, the provision of outstanding service of electricity grid corporations also determine the market share which is also a primary aspect to evaluate the performance of electricity grid corporations. We selected average electricity outage time for urban network users, average electricity outage time for rural network users, customer satisfaction rate, the average time of the urban users' rush repairs to the site, and the average time of the rural users' rush repairs to the site as the important sub-criteria to reflect outstanding service provision.

For energy conservation and environmental protection, since the conventional thermal power generation consumed a great amount of fossil fuel resources and generated large amounts of pollutants, 'No.9 Document' proposed that the installed capacity of renewable energy and grid connection of renewable energy based electricity generation should be increased. Therefore, to reflect energy conservation and environmental protection capacity of electricity grid corporations, newly increased distributed electricity supply, electricity amount replaced by electric power, the reduction of carbon dioxide emissions from electricity generation trading, and comprehensive line loss rate were selected.

\subsection{Sub-Criteria Weights Determination}

In this investigation, to comprehensively consider the preferences of experts and the actual data of selected electricity grid corporations, the weights of sub-criteria were determined via combining subjective weighting method BWM and objective weighting method named entropy weight calculation approach.

\subsubsection{Subjective Weights Results Determined by BWM}

Primarily, five selected experts were required to identify the best and worst sub-criteria. The best one should be the most desirable and critical which can reflect the vital feature of electricity grid corporations, while the worst one should be the opposite one. The best and worst ones picked out by experts are listed in Table 2. 
Then experts should determine the comparison results through comparing the best one with others and comparing others with the worst one via utilizing numbers in 1-9. The greater the number is, the more significant of the best one over others. The comparison results are listed in Tables A2 and A3 in Appendix A.

Thirdly, we can substitute comparison values into the linear Formula (6), and then we can calculate the optimal weights based on experts' preferences utilizing BWM through solving Formula (6) using Lingo 9 software. Taking the comparison results of Expert 1 for the example, through substituting concrete values into Formula (6), we can obtain the following equation:

$$
\begin{aligned}
& \left|w_{4}-2 w_{1}\right| \leq \varepsilon\left|w_{4}-2 w_{2}\right| \leq \varepsilon\left|w_{4}-2 w_{3}\right| \leq \varepsilon\left|w_{4}-w_{4}\right| \leq \varepsilon \\
& \left|w_{4}-9 w_{5}\right| \leq \varepsilon\left|w_{4}-9 w_{6}\right| \leq \varepsilon\left|w_{4}-9 w_{7}\right| \leq \varepsilon\left|w_{4}-3 w_{8}\right| \leq \varepsilon \\
& \left|w_{4}-3 w_{9}\right| \leq \varepsilon\left|w_{4}-4 w_{10}\right| \leq \varepsilon\left|w_{4}-4 w_{11}\right| \leq \varepsilon\left|w_{4}-4 w_{12}\right| \leq \varepsilon \\
& \left|w_{4}-6 w_{13}\right| \leq \varepsilon\left|w_{4}-6 w_{14}\right| \leq \varepsilon\left|w_{4}-5 w_{15}\right| \leq \varepsilon\left|w_{4}-6 w_{16}\right| \leq \varepsilon \\
& \left|w_{4}-6 w_{17}\right| \leq \varepsilon\left|w_{4}-8 w_{18}\right| \leq \varepsilon\left|w_{4}-8 w_{19}\right| \leq \varepsilon\left|w_{4}-8 w_{20}\right| \leq \varepsilon \\
& \left|w_{4}-7 w_{21}\right| \leq \varepsilon\left|w_{1}-8 w_{7}\right| \leq \varepsilon\left|w_{2}-8 w_{7}\right| \leq \varepsilon\left|w_{3}-8 w_{7}\right| \leq \varepsilon \\
& \left|w_{4}-9 w_{7}\right| \leq \varepsilon\left|w_{5}-w_{7}\right| \leq \varepsilon\left|w_{6}-w_{7}\right| \leq \varepsilon\left|w_{7}-w_{7}\right| \leq \varepsilon \\
& \left|w_{8}-7 w_{7}\right| \leq \varepsilon\left|w_{9}-7 w_{7}\right| \leq \varepsilon\left|w_{10}-6 w_{7}\right| \leq \varepsilon\left|w_{11}-6 w_{7}\right| \leq \varepsilon \\
& \left|w_{12}-6 w_{7}\right| \leq \varepsilon\left|w_{13}-4 w_{7}\right| \leq \varepsilon\left|w_{14}-4 w_{7}\right| \leq \varepsilon\left|w_{15}-5 w_{7}\right| \leq \varepsilon \\
& \left|w_{16}-4 w_{7}\right| \leq \varepsilon\left|w_{17}-4 w_{7}\right| \leq \varepsilon\left|w_{18}-2 w_{7}\right| \leq \varepsilon\left|w_{19}-2 w_{7}\right| \leq \varepsilon \\
& \left|w_{20}-2 w_{7}\right| \leq \varepsilon\left|w_{21}-3 w_{7}\right| \leq \varepsilon
\end{aligned}
$$

After obtaining the optimal weights in terms of five experts' preferences, we can calculate the average values of five set optimum weights with regard to each sub-criterion to achieve the subjective weights, and the results are shown in Table 3. The coherent ratio can be computed through Formula (7) via utilizing the calculated data $\xi^{*}$ and coherent indicator displayed in Table 1 . As demonstrated in Table 3 , the coherent ratios are close to 0 , which indicates that the views of experts were coherent.

Table 2. The best and worst sub-criteria picked out by experts.

\begin{tabular}{cll}
\hline Expert Number & \multicolumn{1}{c}{ The Best Sub-Criteria } & \multicolumn{1}{c}{ The Worst Sub-Criteria } \\
\hline 1 & Electricity sales amount (S4) & $\begin{array}{l}\text { Signing rate of contracts for electricity supply and } \\
\text { consuming (S7) }\end{array}$ \\
\hline 2 & Electricity sales amount (S4) & Total amount of electricity grid security events (S9) \\
\hline 3 & Reliability of electricity grid system (S10) & $\begin{array}{l}\text { Signing rate of contracts for electricity supply and } \\
\text { consuming (S7) }\end{array}$ \\
\hline 4 & Reliability of electricity grid system (S10) & $\begin{array}{l}\text { Signing rate of contracts for electricity supply and } \\
\text { consuming (S7) }\end{array}$ \\
\hline 5 & Customer satisfaction rate (S15) & $\begin{array}{l}\text { Signing rate of contracts for electricity supply and } \\
\text { consuming (S7) }\end{array}$ \\
\hline
\end{tabular}

Table 3. Subjective weights computed by BWM.

\begin{tabular}{lcccccc}
\hline \multicolumn{1}{c}{ Sub-Criteria } & E1 & E2 & E3 & E4 & E5 & Average Weight \\
\hline Quick ratio & 0.092 & 0.091 & 0.040 & 0.047 & 0.084 & 0.071 \\
Cost of unit electricity transmission and distribution & 0.092 & 0.091 & 0.040 & 0.047 & 0.084 & 0.071 \\
Revenue of unit electricity sales & 0.092 & 0.091 & 0.040 & 0.047 & 0.084 & 0.071 \\
Electricity sales amount & 0.152 & 0.150 & 0.050 & 0.047 & 0.084 & 0.097 \\
Talent equivalent density & 0.021 & 0.023 & 0.022 & 0.023 & 0.019 & 0.022 \\
Scale of line under construction & 0.021 & 0.023 & 0.022 & 0.023 & 0.021 & 0.022 \\
Signing rate of contracts for electricity supply and consuming & 0.013 & 0.023 & 0.014 & 0.013 & 0.013 & 0.015 \\
Total number of personal safety events & 0.062 & 0.020 & 0.067 & 0.094 & 0.056 & 0.060 \\
Total amount of electricity grid security events & 0.062 & 0.013 & 0.067 & 0.094 & 0.056 & 0.058 \\
Reliability of electricity grid system & 0.046 & 0.061 & 0.165 & 0.154 & 0.033 & 0.092 \\
Proportion of normal state of transmission line & 0.046 & 0.061 & 0.100 & 0.062 & 0.033 & 0.061 \\
Proportion of voltage transformer normal state & 0.046 & 0.061 & 0.100 & 0.062 & 0.033 & 0.061 \\
Average electricity outage time for urban network users & 0.031 & 0.026 & 0.033 & 0.027 & 0.042 & 0.032 \\
Average electricity outage time for rural network users & 0.031 & 0.026 & 0.033 & 0.027 & 0.042 & 0.032 \\
\hline
\end{tabular}


Table 3. Cont.

\begin{tabular}{lcccccc}
\hline \multicolumn{1}{c}{ Sub-Criteria } & E1 & E2 & E3 & E4 & E5 & Average Weight \\
\hline Customer satisfaction rate & 0.037 & 0.030 & 0.033 & 0.031 & 0.134 & 0.053 \\
The average time of the urban users' rush repairs to the site & 0.031 & 0.026 & 0.033 & 0.027 & 0.042 & 0.032 \\
The average time of the rural users' rush repairs to the site & 0.031 & 0.026 & 0.033 & 0.027 & 0.042 & 0.032 \\
Newly increased distributed electricity supply & 0.023 & 0.037 & 0.025 & 0.037 & 0.024 & 0.029 \\
Electricity amount replaced by electric power & 0.023 & 0.037 & 0.025 & 0.037 & 0.024 & 0.029 \\
The reduction of carbon dioxide emissions from electricity & 0.023 & 0.037 & 0.025 & 0.037 & 0.024 & 0.029 \\
generation trading & 0.026 & 0.046 & 0.029 & 0.037 & 0.028 & 0.033 \\
Comprehensive line loss rate & 0.033 & 0.033 & 0.036 & 0.033 & 0.033 & 0.034 \\
$\xi^{*}$ & 0.006 & 0.006 & 0.007 & 0.006 & 0.006 & 0.006 \\
\hline Consistency Ratio, CR & & & &
\end{tabular}

Note: E1 represents Expert 1.

\subsubsection{Objective Weights Results Determined by the Entropy Weight Calculation Approach}

Five provincial electricity grid corporations of China were selected as the evaluated objects named by A, B, C, D, and E. The objective data of all sub-criteria with regard to each electricity grid corporation were collected from National Electricity Grid Corporations Yearbook of China in 2017. To calculate the objective weights utilizing entropy weights calculation approach, we needed to standardize the original data of each sub-criterion with regard to every electricity grid corporation employing Formula (12) and (13). The standardized performance values are illustrated in Table A4 in Appendix A.

Then objective weights were computed via Formula (8)-(11), and the results of objective weights are listed in Table 4.

Table 4. Objective weights determined by entropy weight calculation approach.

\begin{tabular}{lc}
\hline \multicolumn{1}{c}{ Sub-Criteria } & Weights \\
\hline Quick ratio & 0.077 \\
Cost of unit electricity transmission and distribution & 0.032 \\
Revenue of unit electricity sales & 0.039 \\
Electricity sales amount & 0.099 \\
Talent equivalent density & 0.040 \\
Scale of line under construction & 0.045 \\
Signing rate of contracts for electricity supply and consuming & 0.029 \\
Total number of personal safety events & 0.063 \\
Total amount of electricity grid security events & 0.058 \\
Reliability of electricity grid system & 0.026 \\
Proportion of normal state of transmission line & 0.029 \\
Proportion of voltage transformer normal state & 0.061 \\
Average electricity outage time for urban network users & 0.069 \\
Average electricity outage time for rural network users & 0.058 \\
Customer satisfaction rate & 0.034 \\
The average time of the urban users' rush repairs to the site & 0.028 \\
The average time of the rural users' rush repairs to the site & 0.026 \\
Newly increased distributed electricity supply & 0.039 \\
Electricity amount replaced by electric power & 0.028 \\
The reduction of carbon dioxide emissions from electricity generation trading & 0.035 \\
Comprehensive line loss rate & 0.086 \\
\hline
\end{tabular}

\subsubsection{Final Weights Combining Subjective Weights and Objective Weights}

Synthetically taking the preferences of experts and actual data of all electricity grid corporations into consideration, final weights were determined by subjective weights identified by BWM and objective weights calculated by the entropy weight calculation approach through setting the same importance of them. The results of final weights are listed in Table 5. 
Table 5. Final weights for all sub-criteria.

\begin{tabular}{|c|c|c|c|}
\hline Sub-Criteria & Subjective Weights & Objective Weights & Final Weights \\
\hline Quick ratio & 0.071 & 0.077 & 0.074 \\
\hline Cost of unit electricity transmission and distribution & 0.071 & 0.032 & 0.051 \\
\hline Revenue of unit electricity sales & 0.071 & 0.039 & 0.055 \\
\hline Electricity sales amount & 0.097 & 0.099 & 0.098 \\
\hline Talent equivalent density & 0.022 & 0.040 & 0.031 \\
\hline Scale of line under construction & 0.022 & 0.045 & 0.033 \\
\hline Signing rate of contracts for electricity supply and consuming & 0.015 & 0.029 & 0.022 \\
\hline Total number of personal safety events & 0.060 & 0.063 & 0.061 \\
\hline Total amount of electricity grid security events & 0.058 & 0.058 & 0.058 \\
\hline Reliability of electricity grid system & 0.092 & 0.026 & 0.059 \\
\hline Proportion of normal state of transmission line & 0.061 & 0.029 & 0.045 \\
\hline Proportion of voltage transformer normal state & 0.061 & 0.061 & 0.061 \\
\hline Average electricity outage time for urban network users & 0.032 & 0.069 & 0.050 \\
\hline Average electricity outage time for rural network users & 0.032 & 0.058 & 0.045 \\
\hline Customer satisfaction rate & 0.053 & 0.034 & 0.044 \\
\hline The average time of the urban users' rush repairs to the site & 0.032 & 0.028 & 0.030 \\
\hline The average time of the rural users' rush repairs to the site & 0.032 & 0.026 & 0.029 \\
\hline Newly increased distributed electricity supply & 0.029 & 0.039 & 0.034 \\
\hline Electricity amount replaced by electric power & 0.029 & 0.028 & 0.028 \\
\hline The reduction of carbon dioxide emissions from electricity generation trading & 0.029 & 0.035 & 0.032 \\
\hline Comprehensive line loss rate & 0.033 & 0.086 & 0.060 \\
\hline
\end{tabular}

\subsection{Comprehensive Performance Evaluation of Five Electricity Grid Corporations Utilizing VIKOR}

On the basis of the final weights obtained above, the comprehensive evaluation model can be denoted:

$$
B=\left(\begin{array}{ccccc}
0.074 & 0.068 & 0.470 & 0 & 1 \\
1 & 0.370 & 0 & 0.756 & 0.607 \\
0.347 & 0.920 & 1 & 0 & 0.320 \\
1 & 0.139 & 0.006 & 0 & 0.176 \\
1 & 0.375 & 0 & 0.625 & 0.250 \\
1 & 0.824 & 0 & 0.321 & 0.203 \\
0.671 & 0.948 & 1 & 0 & 0.539 \\
1 & 0 & 0.500 & 1 & 0 \\
1 & 1 & 1 & 0 & 0 \\
0.896 & 0.933 & 0.995 & 0 & 1 \\
0 & 1 & 1 & 0.608 & 0.608 \\
0.553 & 0.873 & 1 & 0 & 0 \\
0.018 & 0 & 0.248 & 0.513 & 1 \\
0.033 & 1 & 0 & 0.423 & 0.764 \\
0 & 1 & 0.354 & 0.497 & 0.779 \\
0.650 & 0.650 & 1 & 0 & 0.650 \\
0.768 & 0.821 & 1 & 0 & 0.821 \\
0.365 & 0.311 & 0 & 1 & 0.486 \\
0 & 0.893 & 0.585 & 0.944 & 1 \\
0.883 & 0.372 & 0 & 1 & 0.460 \\
0.118 & 0.038 & 0 & 0.247 & 1
\end{array}\right)
$$

Then, we need to find the positive and negative ideal values $X^{+}$and $X^{-}$in accordance with Formula (14).

After that, the group benefit results $S_{j}$, the individual regret results $R_{j}$, as well as the compromise sorting values $Q_{j}$ of five electricity grid corporations were computed via Formula (15)-(17). The results of them are illustrated in Table 6. 
Table 6. VIKOR evaluation results of five electricity grid corporations.

\begin{tabular}{cccc}
\hline Alternatives & $\boldsymbol{S}_{\boldsymbol{j}}$ & $\boldsymbol{R}_{\boldsymbol{j}}$ & $\boldsymbol{Q}_{\boldsymbol{j}}$ \\
\hline $\mathrm{A}$ & 0.45 & 0.07 & 0 \\
$\mathrm{~B}$ & 0.46 & 0.084 & 0.29 \\
$\mathrm{C}$ & 0.53 & 0.10 & 0.67 \\
$\mathrm{D}$ & 0.67 & 0.10 & 1 \\
$\mathrm{E}$ & 0.47 & 0.08 & 0.25 \\
\hline
\end{tabular}

Then five electricity grid corporations can be ranked through comparing values of $S_{j}, R_{j}$, and $Q_{j}$, and the electricity grid corporation with superiority performance can be discovered. In terms of the results and rankings of $S_{j}, R_{j}$, and $Q_{j}$ demonstrated in Tables 6 and 7, electricity grid corporations $\mathrm{A}$ and E satisfied the two qualifications of VIKOR, hence, electricity grid corporation A performed the best among five selected alternatives in terms of two requirements mentioned in Section 2.4. Electricity grid corporations $\mathrm{E}$ and $\mathrm{B}$ had close performance, which were better than electricity grid corporations $\mathrm{C}$ and $\mathrm{D}$.

Table 7. Rankings of $S_{j}, R_{j}$, and $Q_{j}$ for five electricity grid corporations.

\begin{tabular}{cccc}
\hline Alternatives & $\boldsymbol{S}_{\boldsymbol{j}}$ & $\boldsymbol{R}_{\boldsymbol{j}}$ & $\boldsymbol{Q}_{j}$ \\
\hline $\mathrm{A}$ & 1 & 1 & 1 \\
$\mathrm{~B}$ & 2 & 3 & 3 \\
$\mathrm{C}$ & 4 & 4 & 4 \\
$\mathrm{D}$ & 5 & 5 & 5 \\
$\mathrm{E}$ & 3 & 2 & 2 \\
\hline
\end{tabular}

\section{Discussion and Policy Implications}

\subsection{Discussion about Comprehensive Performance Evaluation Results}

The comprehensive performance evaluation of five selected electricity grid corporations were assessed by a novel MCDM model integrating Fuzzy-Delphi, BWM, entropy weight calculation approach, and VIKOR. And the assessment results illustrated that electricity grid corporation A had superior performance over other four electricity grid corporations. To further understand the empirical results, we will conduct a depth discussion on subjective weights, objective weights, and the evaluated values of every electricity grid corporation for every sub-criterion.

For subjective weights determined by BWM, experts exerted more significance on profitability capacity, safety production, and electricity supply reliability. The weight of electricity sales amount reached 0.097 ranking, the first which can reflect the profitability of an electricity grid corporation, followed by the weight of reliability of electricity grid system with 0.092 . Considering about the original monopoly position of electricity grid corporations in electricity market, some experts pay less attention on developing capacity of electricity grid corporations, the subjective weights of talent equivalent density, scale of line under construction, and signing rate of contracts for electricity supply and consuming ranked the last three with $0.022,0.022$, and 0.015 . However, under the context of electricity market reform, with the emergence of electricity selling enterprises, some experts highlighted the significance of providing outstanding services for electricity consumers, hence, the weight of customer satisfaction rate was relatively high with 0.053 .

For objective weights calculated using the entropy weight calculation approach, based on actual data of selected electricity grid corporations, profitability aspect, energy conservation and environmental protection perspective, outstanding service provision criterion, and safety production capacity were emphasized. The objective weight of electricity sales amount also ranked the first with 0.099, followed by comprehensive line loss rate attributed to energy conservation and environmental protection perspective with 0.086 . The weights of average electricity outage time for urban network 
users and total number of personal safety events ranked the fourth and fifth with 0.069 and 0.063 , respectively. However, in accordance with the actual data, the reliability of electricity grid system was the least important with objective weight 0.026 , which was quite different from subjective weights. Additionally, the objective weights of developing capacity criterion were relatively high.

For final weights integrating subjective weights and objective weights, the weights of sub-criteria attributed to profitability aspect, safety production capacity, and electricity supply reliability ranked at the front, which comprehensively combined experts' views and the actual development situation of electricity grid corporations. The last one is the signing rate of contracts for electricity supply and consuming with a ranking of 0.22 .

In terms of the final weights of all sub-criteria, since the electricity grid corporation A was superior in the profitability aspect (especially in electricity sales amount) and safety production capacity criterion, it had the best comprehensive performance among five selected electricity grid corporations.

\subsection{Comparative Analysis}

This section conducts a comparative analysis utilizing the existing and commonly used method, which is TOPSIS method, to verify the effectiveness of the established MCDM methodology in this investigation. The basic theory of the TOPSIS is that the selected evaluated object should have the minimum distance from the positive ideal solution and the maximum distance from the negative ideal solution. The procedure of the TOPSIS method is elaborated in [7]. The performance values utilized in the TOPSIS method are listed in Table A4, and the weights of sub-criteria utilized in the TOPSIS method are elaborated in Table 5, combining the subjective weights and objective weights. Then the rankings and results of five electricity grid corporations are illustrated as: A (0.545) > E (0.502) > B $(0.485)>\mathrm{C}(0.468)>\mathrm{D}(0.358)$. It can be discovered that the ranking results of the TOPSIS method were the same as that of the established MCDM methodology in this investigation. Hence, the effectiveness of the established MCDM methodology can be verified and it is applicable and valid to be utilized in comprehensive performance evaluation of electricity grid corporations.

\subsection{Policy Implications}

In accordance with the results of the comprehensive performance evaluation of electricity grid corporations, the following policy implications are put forward to improve the comprehensive performance of electricity grid corporations.

(1) Providing more comprehensive outstanding services to expand market share and increase electricity sales amount. After the new round electricity industry reform, electricity grid enterprises mainly engaged in the purchase and sale of electricity business, such as providing strategy consultation of selling and trading electricity. Meanwhile, to attract more electricity consumers, electricity grid enterprises will provide energy management services. Considering the weight calculation results that highlighted the significance of electricity sales amount and outstanding services, electricity grid corporations should not only guarantee the existing outstanding services, but also carry out different value-added services in accordance with their own characteristics and advantages to meet the demands of various types of consumers, such as customizing electricity saving strategies for users and formulating comprehensive energy utilization plan for enterprises and families using multiple energy sources. Through providing more comprehensive outstanding services, more electricity users are attracted by electricity grid corporations so that the electricity sales amount can be increased and the performance of electricity grid corporations can be improved.

(2) Optimizing the management of effective assets to improve the profitability of electricity grid corporations. In terms of the weight computation results, the significance of sub-criteria attributed to the profitability of electricity grid corporations were highlighted. The revenue of unit electricity sales and cost of unit electricity transmission and distribution were determined by the permitted 
income and permitted cost of electricity grid corporations, which greatly depended on the management level of effective assets of electricity grid corporations. Aiming at improving the profitability, the electricity grid corporations should improve the management level of effective assets by eliminating over-aged assets and reducing maintenance costs to decrease permitted cost and increasing investment on effective assets to enhance permitted income so that the profitability can be improved.

(3) Maintaining the stable operation of electricity network to improve electricity supply reliability. The new round of electricity industry reform encouraged the orderly investment of social capital on an incremental distribution network. In the process of developing the incremental distribution network, the interactive use of the new distribution network and the original network will put forward a severe test for the stable and reliable electricity supply. The electricity grid corporations should make better communication with the operators of the incremental distribution network to clarify the responsibilities of the maintenance and establish a coordination mechanism. Hence, when the equipment and lines of distribution network are out of order, the corresponding maintainers can make urgent repairs to guarantee reliable and stable electricity supply so that the operation performance of electricity grid corporations can be ensured.

\section{Conclusions}

With the process of the new round reform of electricity market in China, a large amount of electricity sales companies has emerged in some provinces, and the reform of transmission and distribution tariffs are also in progress. Under such new market context, electricity grid corporations are required to update their operational strategies and improve comprehensive performance to adapt to the fierce competition in the electricity market. Considering this, this paper established a novel MCDM model combining Fuzzy-Delphi, the BWM, the entropy weight calculation approach, and VIKOR method to make an evaluation on the comprehensive performances of five selected provincial electricity grid corporations, which can help decision makers get a better acknowledgement of the performance of each aspect and formulate novel market strategies to guarantee the sustainable development of their corporations. The primary conclusions for this investigation are summarized as below.

(1) The comprehensive performance assessment index system was constructed in accordance with Fuzzy-Delphi approach based on the preferences of experts, which was composed of 21 significant sub-criteria from the aspects of profitability capacity, development capacity, safety production capacity, electricity supply reliability, outstanding service provision, and energy conservation and environmental protection with eight minimum type sub-criteria.

(2) The sub-criteria weights were computed by combining subjective weights determined by BWM and objective weights computed by the entropy weight calculation approach. The weights of sub-criteria attributed to profitability capacity, safety production capacity, and electricity supply reliability ranked at the front, which comprehensively combined experts' views and actual developing situation of electricity grid corporations.

(3) The comprehensive performance evaluation model was established based on VIKOR. Since the electricity grid corporation A was superior in profitability capacity (especially in electricity sales amount) and safety production capacity criterion, it was the best electricity grid corporations with superior comprehensive performance among five selected alternatives, and the ranking results of the established MCDM model were the same as that of the TOPSIS method through comparative analysis.

In accordance with the results of comprehensive evaluation of electricity grid corporations, several policy implications were put forward to improve the comprehensive performance of electricity grid corporations, such as providing more comprehensive outstanding services to expand market share and increase electricity sales amount, optimizing the management of effective assets to improve the 
profitability of electricity grid corporations, and maintaining the stable operation of electricity network to improve electricity supply reliability.

The established novel MCDM based on Fuzzy-Delphi, the BWM, the entropy weight calculation approach, and VIKOR approach for comprehensive performance evaluation on electricity grid corporations is practical and rational. With the further advancement of the reform for the electricity market, the index system for comprehensive performance evaluation needs to be renewed, and the weights for all sub-criteria need to be adjusted.

Author Contributions: H.Z. (Huiru Zhao) proposed the conceptual framework of this investigation. H.Z. (Haoran Zhao) carried out the empirical analysis and completed the paper. S.G. modified the article and provided some important recommendations.

Funding: This research was funded by the Major State Research and Development Program of China grant number 2016YFB0900501 and the Fundamental Research Funds for the Central Universities grant number JB2017205.

Acknowledgments: This investigation is supported by the Major State Research and Development Program of China under Grant No.2016YFB0900501 and the Fundamental Research Funds for the Central Universities (JB2017205).

Conflicts of Interest: The authors declare no conflicts of interest. 


\section{Appendix A.}

Table A1. The Fuzzy-Delphi approach results.

\begin{tabular}{|c|c|c|c|c|c|c|c|c|}
\hline \multirow{2}{*}{ Criteria } & \multirow{2}{*}{ Original Sub-Criteria } & \multicolumn{3}{|c|}{ Conservative Value } & \multicolumn{3}{|c|}{ Positive Value } & \multirow{2}{*}{$\begin{array}{c}\text { Coherent Value } \\
G_{i}\end{array}$} \\
\hline & & $C_{L}^{i}$ & $C_{M}^{i}$ & $C_{U}^{i}$ & $P_{L}^{i}$ & $P_{M}^{i}$ & $P_{U}^{i}$ & \\
\hline \multirow{7}{*}{ Profitability aspect } & Total assets turnover days & 1 & 1.78 & 3 & 4 & 4.57 & 6 & $3.18<4.66$ \\
\hline & Total profit & 1 & 2.46 & 4 & 4 & 5.31 & 6 & $3.89<4.66$ \\
\hline & Asset liability ratio & 1 & 3.17 & 4 & 5 & 6.01 & 7 & $4.59<4.66$ \\
\hline & Quick ratio & 3 & 4.26 & 7 & 7 & 8.21 & 9 & $6.24>4.66$ \\
\hline & Cost of unit electricity transmission and distribution & 3 & 4.57 & 7 & 8 & 9.01 & 10 & $6.79>4.66$ \\
\hline & Revenue of unit electricity sales & 2 & 4.45 & 7 & 8 & 9.23 & 10 & $6.84>4.66$ \\
\hline & Electricity sales amount & 3 & 5.22 & 7 & 8 & 8.84 & 10 & $7.03>4.66$ \\
\hline \multirow{6}{*}{ Development capacity } & Talent equivalent density & 3 & 5.47 & 7 & 8 & 9.13 & 10 & $7.30>4.66$ \\
\hline & Total labor productivity & 2 & 3.01 & 4 & 5 & 6.17 & 8 & $4.59<4.66$ \\
\hline & Scale of line under construction & 3 & 4.87 & 6 & 7 & 8.53 & 10 & $6.7>4.66$ \\
\hline & Scale of power transformation station under construction & 1 & 3.02 & 4 & 5 & 6.07 & 7 & $4.55<4.66$ \\
\hline & Signing rate of contracts for electricity supply and consuming & 3 & 5.47 & 7 & 8 & 9.16 & 10 & $7.32>4.66$ \\
\hline & Industry expansion capacity & 2 & 3.12 & 4 & 5 & 5.77 & 7 & $4.45<4.66$ \\
\hline \multirow{4}{*}{ Safety production capacity } & Total number of personal safety events & 3 & 5.21 & 6 & 7 & 8.82 & 10 & $7.02>4.66$ \\
\hline & Total amount of electricity grid security events & 3 & 5.29 & 7 & 8 & 9.16 & 10 & $7.23>4.66$ \\
\hline & 100 days safety record & 1 & 2.97 & 4 & 5 & 6.12 & 7 & $4.55<4.66$ \\
\hline & Total amount of devices security events & 1 & 2.77 & 4 & 5 & 5.92 & 7 & $4.35<4.66$ \\
\hline \multirow{7}{*}{ Electricity supply reliability } & Reliability of electricity grid system & 3 & 4.99 & 6 & & 8.55 & 10 & $6.77>4.66$ \\
\hline & Proportion of normal state of transmission line & 3 & 4.82 & 6 & 7 & 8.73 & 10 & $6.78>4.66$ \\
\hline & Proportion of voltage transformer normal state & 4 & 6.14 & 7 & 8 & 9.11 & 10 & $7.63>4.66$ \\
\hline & Central point voltage qualification rate & 1 & 2.01 & 3 & 4 & 5.16 & 7 & $3.59<4.66$ \\
\hline & Average unplanned outage time & 1 & 2.05 & 3 & 4 & 4.95 & 6 & $3.50<4.66$ \\
\hline & Average fault outage time of transmission network & 1 & 1.95 & 3 & 4 & 5.04 & 6 & $3.50<4.66$ \\
\hline & Number of unplanned outage accidents at the access point of the transmission network & 1 & 2.31 & 4 & 4 & 5.33 & 7 & $3.82<4.66$ \\
\hline \multirow{9}{*}{ Outstanding service provision } & Average electricity outage time for urban network users & 3 & 5.69 & 7 & 8 & 9.04 & 10 & $7.37>4.66$ \\
\hline & Average electricity outage time for rural network users & 3 & 5.28 & 7 & 8 & 8.96 & 10 & $7.12>4.66$ \\
\hline & Qualified rate of urban comprehensive electricity supply voltage & 1 & 2.99 & 4 & 5 & 5.87 & 7 & $4.43<4.66$ \\
\hline & Qualified rate of rural comprehensive electricity supply voltage & 1 & 2.02 & 4 & 5 & 6.34 & 8 & $4.18<4.66$ \\
\hline & Timely handling rate of customer complaint & 1 & 2.89 & 4 & 5 & 5.91 & 7 & $4.40<4.66$ \\
\hline & Standard rate of customer service expansion time limit & 1 & 1.34 & 3 & 4 & 5.16 & 7 & $3.25<4.66$ \\
\hline & Customer satisfaction rate & 3 & 5.18 & 8 & 8 & 9.12 & 10 & $7.15>4.66$ \\
\hline & The average time of the urban users' rush repairs to the site & 3 & 4.96 & 6 & 7 & 8.98 & 10 & $6.97>4.66$ \\
\hline & The average time of the rural users' rush repairs to the site & 3 & 5.05 & 7 & 8 & 9.12 & 10 & $7.09>4.66$ \\
\hline \multirow{7}{*}{$\begin{array}{l}\text { Energy conservation and } \\
\text { environmental protection }\end{array}$} & Clean electricity transmission and loss level & 1 & 2.01 & 4 & 4 & 5.37 & 6 & $3.69<4.66$ \\
\hline & Newly increased installed equipment of renewable energy & 1 & 1.88 & 3 & 4 & 4.9 & 6 & $3.39<4.66$ \\
\hline & Accumulative construction of electric vehicle charging and replacement electricity station & 1 & 3.01 & 4 & 5 & 6.19 & 7 & $4.6<4.66$ \\
\hline & Newly increased distributed electricity supply & 2 & 5.49 & 7 & 8 & 9.33 & 10 & $7.41>4.66$ \\
\hline & Electricity amount replaced by electric power & 3 & 6.33 & 8 & 8 & 9.11 & 10 & $7.72>4.66$ \\
\hline & The reduction of carbon dioxide emissions from electricity generation trading & 3 & 6.49 & 8 & 8 & 9.14 & 10 & $7.82>4.66$ \\
\hline & Comprehensive line loss rate & 3 & 5.99 & 8 & 8 & 8.97 & 10 & $7.48>4.66$ \\
\hline
\end{tabular}


Table A2. Comparison results of the best one over others.

\begin{tabular}{|c|c|c|c|c|c|}
\hline Expert Number & 1 & 2 & 3 & 4 & 5 \\
\hline The best sub-criteria & $\mathrm{S} 4$ & $\mathrm{~S} 4$ & S10 & S10 & S15 \\
\hline Quick ratio & 2 & 2 & 5 & 4 & 2 \\
\hline Cost of unit electricity transmission and distribution & 2 & 2 & 5 & 4 & 2 \\
\hline Revenue of unit electricity sales & 2 & 2 & 5 & 4 & 2 \\
\hline Electricity sales amount & 1 & 1 & 4 & 4 & 2 \\
\hline Talent equivalent density & 9 & 8 & 9 & 8 & 9 \\
\hline Scale of line under construction & 9 & 8 & 9 & 8 & 8 \\
\hline Signing rate of contracts for electricity supply and consuming & 9 & 8 & 9 & 9 & 8 \\
\hline Total number of personal safety events & 3 & 9 & 3 & 2 & 3 \\
\hline Total amount of electricity grid security events & 3 & 9 & 3 & 2 & 3 \\
\hline Reliability of electricity grid system & 4 & 3 & 1 & 1 & 5 \\
\hline Proportion of normal state of transmission line & 4 & 3 & 2 & 3 & 5 \\
\hline Proportion of voltage transformer normal state & 4 & 3 & 2 & 3 & 5 \\
\hline Average electricity outage time for urban network users & 6 & 7 & 6 & 7 & 4 \\
\hline Average electricity outage time for rural network users & 6 & 7 & 6 & 7 & 4 \\
\hline Customer satisfaction rate & 5 & 6 & 6 & 6 & 1 \\
\hline The average time of the urban users' rush repairs to the site & 6 & 7 & 6 & 7 & 4 \\
\hline The average time of the rural users' rush repairs to the site & 6 & 7 & 6 & 7 & 4 \\
\hline Newly increased distributed electricity supply & 8 & 5 & 8 & 5 & 7 \\
\hline Electricity amount replaced by electric power & 8 & 5 & 8 & 5 & 7 \\
\hline The reduction of carbon dioxide emissions from electricity generation trading & 8 & 5 & 8 & 5 & 7 \\
\hline Comprehensive line loss rate & 7 & 4 & 7 & 5 & 6 \\
\hline
\end{tabular}


Table A3. Comparison results of others over the worst one.

\begin{tabular}{|c|c|c|c|c|c|}
\hline Expert Number & 1 & 2 & 3 & 4 & 5 \\
\hline The worst sub-criteria & S7 & S9 & S7 & S7 & S7 \\
\hline Quick ratio & 8 & 8 & 5 & 6 & 8 \\
\hline Cost of unit electricity transmission and distribution & 8 & 8 & 5 & 6 & 8 \\
\hline Revenue of unit electricity sales & 8 & 8 & 5 & 6 & 8 \\
\hline Electricity sales amount & 9 & 9 & 6 & 6 & 8 \\
\hline Talent equivalent density & 1 & 2 & 1 & 2 & 1 \\
\hline Scale of line under construction & 1 & 2 & 1 & 2 & 2 \\
\hline Signing rate of contracts for electricity supply and consuming & 1 & 2 & 1 & 1 & 2 \\
\hline Total number of personal safety events & 7 & 1 & 7 & 8 & 7 \\
\hline Total amount of electricity grid security events & 7 & 1 & 7 & 8 & 7 \\
\hline Reliability of electricity grid system & 6 & 7 & 9 & 9 & 5 \\
\hline Proportion of normal state of transmission line & 6 & 7 & 8 & 7 & 5 \\
\hline Proportion of voltage transformer normal state & 6 & 7 & 8 & 7 & 5 \\
\hline Average electricity outage time for urban network users & 4 & 3 & 4 & 3 & 6 \\
\hline Average electricity outage time for rural network users & 4 & 3 & 4 & 3 & 6 \\
\hline Customer satisfaction rate & 5 & 4 & 4 & 4 & 9 \\
\hline The average time of the urban users' rush repairs to the site & 4 & 3 & 4 & 3 & 6 \\
\hline The average time of the rural users' rush repairs to the site & 4 & 3 & 4 & 3 & 6 \\
\hline Newly increased distributed electricity supply & 2 & 5 & 2 & 5 & 3 \\
\hline Electricity amount replaced by electric power & 2 & 5 & 2 & 5 & 3 \\
\hline The reduction of carbon dioxide emissions from electricity generation trading & 2 & 5 & 2 & 5 & 3 \\
\hline Comprehensive line loss rate & 3 & 6 & 3 & 5 & 4 \\
\hline
\end{tabular}

Table A4. The standardized performance values of all sub-criteria with regard to five electricity grid corporations.

\begin{tabular}{|c|c|c|c|c|c|}
\hline Sub-Criteria & $\mathbf{A}$ & B & $\mathrm{C}$ & $\mathbf{D}$ & E \\
\hline Quick ratio & 0.074 & 0.068 & 0.470 & 0 & 1 \\
\hline Cost of unit electricity transmission and distribution & 1 & 0.370 & 0 & 0.756 & 0.607 \\
\hline Revenue of unit electricity sales & 0.347 & 0.920 & 1 & 0 & 0.320 \\
\hline Electricity sales amount & 1 & 0.139 & 0.006 & 0 & 0.176 \\
\hline Talent equivalent density & 1 & 0.375 & 0 & 0.625 & 0.250 \\
\hline Scale of line under construction & 1 & 0.824 & 0 & 0.321 & 0.203 \\
\hline Signing rate of contracts for electricity supply and consuming & 0.671 & 0.948 & 1 & 0 & 0.539 \\
\hline Total number of personal safety events & 1 & 0 & 0.500 & 1 & 0 \\
\hline Total amount of electricity grid security events & 1 & 1 & 1 & 0 & 0 \\
\hline Reliability of electricity grid system & 0.896 & 0.933 & 0.995 & 0 & 1 \\
\hline Proportion of normal state of transmission line & 0 & 1 & 1 & 0.608 & 0.608 \\
\hline Proportion of voltage transformer normal state & 0.553 & 0.873 & 1 & 0 & 0 \\
\hline Average electricity outage time for urban network users & 0.018 & 0 & 0.248 & 0.513 & 1 \\
\hline Average electricity outage time for rural network users & 0.033 & 1 & 0 & 0.423 & 0.764 \\
\hline Customer satisfaction rate & 0 & 1 & 0.354 & 0.497 & 0.779 \\
\hline The average time of the urban users' rush repairs to the site & 0.650 & 0.650 & 1 & 0 & 0.650 \\
\hline The average time of the rural users' rush repairs to the site & 0.768 & 0.821 & 1 & 0 & 0.821 \\
\hline Newly increased distributed electricity supply & 0.365 & 0.311 & 0 & 1 & 0.486 \\
\hline Electricity amount replaced by electric power & 0 & 0.893 & 0.585 & 0.944 & 1 \\
\hline The reduction of carbon dioxide emissions from electricity generation trading & 0.883 & 0.372 & 0 & 1 & 0.460 \\
\hline Comprehensive line loss rate & 0.118 & 0.038 & 0 & 0.247 & 1 \\
\hline
\end{tabular}

\section{References}

1. Sun, W.; Xu, Y. Financial security evaluation of the electric power industry in China based on a back propagation neural network optimized by genetic algorithm. Energy 2016, 101, 366-379. [CrossRef]

2. Shiu, A.; Lam, P.L. Electricity consumption and economic growth in China. Energy Policy 2004, 32, 47-54. [CrossRef]

3. Tang, Y.; Cao, J.; Guo, C.; Cao, Y.; Han, Z. Research and Implementation of Power Grid Enterprise Application Integration Based on Services-oriented Architecture. Autom. Electr. Power Syst. 2008, 14, 012.

4. Meng, Y.; Wu, J.; Wang, F. Study on Reform of Cost Management and Control for Power Grid Enterprise. Electr. Power Technol. Econ. 2006, 2, 019.

5. Fang, X.; Misra, S.; Xue, G.; Yang, D. Smart grid-The new and improved power grid: A survey. IEEE Commun. Surv. Tutor. 2012, 14, 944-980. [CrossRef] 
6. Zeng, M.; Yang, Y.; Wang, L.; Sun, J. The power industry reform in China 2015: Policies, evaluations and solutions. Renew. Sustain. Energy Rev. 2016, 57, 94-110. [CrossRef]

7. You, P.; Guo, S.; Zhao, H.; Zhao, H. Operation Performance Evaluation of Power Grid Enterprise Using a Hybrid BWM-TOPSIS Method. Sustainability 2017, 9, 2329. [CrossRef]

8. Zeng, B.; Ouyang, S.; Zhang, J.; Shi, H.; Wu, G.; Zeng, M. An analysis of previous blackouts in the world: Lessons for China's power industry. Renew. Sustain. Energy Rev. 2015, 42, 1151-1163.

9. Zheng, Y.; Hu, Z.; Wang, J.; Wen, Q. IRSP (integrated resource strategic planning) with interconnected smart grids in integrating renewable energy and implementing DSM (demand side management) in China. Energy 2014, 76, 863-874. [CrossRef]

10. Shen, J.; Luo, C. Overall review of renewable energy subsidy policies in China-Contradictions of intentions and effects. Renew. Sustain. Energy Rev. 2015, 41, 1478-1488. [CrossRef]

11. Ren, L.; Zhao, X.; Yu, X.; Zhang, Y. Cost-benefit evolution for concentrated solar power in China. J. Clean. Prod. 2018, 190, 471-482.

12. The State Council of the People's Republic of China. Relative Policies on Deepening the Reform of Power Industry. Available online: http:/ / www.gov.cn/zhengce/xxgkzl.htm (accessed on 29 May 2018).

13. Zhou, K.; Yang, S. Demand side management in China: The context of China's power industry reform. Renew. Sustain. Energy Rev. 2015, 47, 954-965. [CrossRef]

14. Zhang, S.; Jiao, Y.; Chen, W. Demand-side management (DSM) in the context of China's on-going power sector reform. Energy Policy 2017, 100, 1-8. [CrossRef]

15. Yu, D.; Qiu, H.; Yuan, X.; Lin, Y.; Ding, Y. Roadmap of Retail Electricity Market Reform in China: Assisting in Mitigating Wind Energy Curtailment; IOP Conference Series: Earth and Environmental Science; IOP Publishing: Bristol, UK, 2017; Volume 52.

16. You, Y.Q.; Jie, T. A study of the operation efficiency and cost performance indices of power-supply companies in China based on a dynamic network slacks-based measure model. Omega 2016, 60, 85-97. [CrossRef]

17. Yazdani, M.; Chatterjee, P.; Zavadskas, E.K.; Zolfanid, S.H. Integrated QFD-MCDM framework for green supplier selection. J. Clean. Prod. 2017, 142, 3728-3740. [CrossRef]

18. Büyüközkan, G.; Göçer, F. Application of a new combined intuitionistic fuzzy MCDM approach based on axiomatic design methodology for the supplier selection problem. Appl. Soft Comput. 2017, 52, 1222-1238. [CrossRef]

19. Hamdan, S.; Cheaitou, A. Supplier selection and order allocation with green criteria: An MCDM and multi-objective optimization approach. Comput. Oper. Res. 2017, 81, 282-304. [CrossRef]

20. Kumar, A.; Sah, B.; Singh, A.R.; Deng, Y.; He, X.; Kumar, P.; Bansald, R.C. A review of multi criteria decision making (MCDM) towards sustainable renewable energy development. Renew. Sustain. Energy Rev. 2017, 69, 596-609. [CrossRef]

21. Çolak, M.; Kaya, İ. Prioritization of renewable energy alternatives by using an integrated fuzzy MCDM model: A real case application for Turkey. Renew. Sustain. Energy Rev. 2017, 80, 840-853. [CrossRef]

22. Abaei, M.M.; Arzaghi, E.; Abbassi, R.; Garaniya, V.; Penesis, I. Developing a novel risk-based methodology for multi-criteria decision making in marine renewable energy applications. Renew. Energy 2017, 102, 341-348. [CrossRef]

23. Fetanat, A.; Khorasaninejad, E. A novel hybrid MCDM approach for offshore wind farm site selection: A case study of Iran. Ocean Coast. Manag. 2015, 109, 17-28. [CrossRef]

24. Sánchez-Lozano, J.M.; García-Cascales, M.S.; Lamata, M.T. GIS-based onshore wind farm site selection using Fuzzy Multi-Criteria Decision Making methods. Evaluating the case of Southeastern Spain. Appl. Energy 2016, 171, 86-102. [CrossRef]

25. Latinopoulos, D.; Kechagia, K. A GIS-based multi-criteria evaluation for wind farm site selection. A regional scale application in Greece. Renew. Energy 2015, 78, 550-560. [CrossRef]

26. Yoon, K.P.; Hwang, C.L. Multiple Attribute Decision Making: An Introduction; Sage Publications: Thousand Oaks, CA, USA, 1995; Volume 104.

27. Dai, S.; Niu, D. Comprehensive Evaluation of the Sustainable Development of Power Grid Enterprises Based on the Model of Fuzzy Group Ideal Point Method and Combination Weighting Method with Improved Group Order Relation Method and Entropy Weight Method. Sustainability 2017, 9, 1900.

28. Wang, Q.; Dai, H.N.; Wang, H. A Smart MCDM Framework to Evaluate the Impact of Air Pollution on City Sustainability: A Case Study from China. Sustainability 2017, 9, 911. [CrossRef] 
29. Shen, F.; Ma, X.; Li, Z.; Xu, Z.; Cai, D. An extended intuitionistic fuzzy TOPSIS method based on a new distance measure with an application to credit risk evaluation. Inf. Sci. 2018, 428, 105-119. [CrossRef]

30. Opricovic, S. Multicriteria Optimization of Civil Engineering Systems. PhD. Thesis, Faculty of Civil Engineering, University of Belgrade, Belgrade, Serbia, 1998.

31. Zhao, H.; Zhao, H.; Guo, S. Evaluating the comprehensive benefit of eco-industrial parks by employing multi-criteria decision making approach for circular economy. J. Clean. Prod. 2017, 142, 2262-2276. [CrossRef]

32. Saaty, T.L. What is the analytic hierarchy process? In Mathematical Models for Decision Support; Springer: Berlin/Heidelberg, Germany, 1988; pp. 109-121.

33. Maystre, L.Y.; Pictet, J.; Simos, J. Méthodes Multicritères ELECTRE: Description, Conseils Pratiques et CasD'application à la Gestion Environnementale; PPUR Presses Polytechniques: Lausanne, Switzerland, 1994; Volume 8.

34. Karsak, E.E.; Dursun, M. An integrated fuzzy MCDM approach for supplier evaluation and selection. Comput. Ind. Eng. 2015, 82, 82-93. [CrossRef]

35. Mardani, A.; Jusoh, A.; Zavadskas, E.K. Fuzzy multiple criteria decision-making techniques and applications-Two decades review from 1994 to 2014. Expert Syst. Appl. 2015, 42, 4126-4148. [CrossRef]

36. Rezaei, J. Best-worst multi-criteria decision-making method. Omega 2015, 53, 49-57. [CrossRef]

37. Rezaei, J. Best-worst multi-criteria decision-making method: Some properties and a linear model. Omega 2016, 64, 126-130. [CrossRef]

38. Rezaei, J.; Nispeling, T.; Sarkis, J.; Tavasszy, L. A supplier selection life cycle approach integrating traditional and environmental criteria using the best worst method. J. Clean. Prod. 2016, 135, 577-588. [CrossRef]

39. Hafezalkotob, A.; Hafezalkotob, A. A novel approach for combination of individual and group decisions based on fuzzy best-worst method. Appl. Soft Comput. 2017, 59, 316-325. [CrossRef]

40. Ren, J.; Liang, H.; Chan, F.T.S. Urban sewage sludge, sustainability, and transition for Eco-City: Multi-criteria sustainability assessment of technologies based on best-worst method. Technol. Forecast. Soc. Chang. 2017, 116, 29-39. [CrossRef]

41. Guo, S.; Zhao, H. Fuzzy best-worst multi-criteria decision-making method and its applications. Knowl. Based Syst. 2017, 121, 23-31. [CrossRef]

42. Ahmadi, H.B.; Kusi-Sarpong, S.; Rezaei, J. Assessing the social sustainability of supply chains using Best Worst Method. Resour. Conserv. Recycl. 2017, 126, 99-106. [CrossRef]

43. Chitsaz, N.; Azarnivand, A. Water scarcity management in arid regions based on an extended multiple criteria technique. Water Resour. Manag. 2017, 31, 233-250. [CrossRef]

44. Gupta, H. Evaluating service quality of airline industry using hybrid best worst method and VIKOR. J. Air Transp. Manag. 2018, 68, 35-47. [CrossRef]

45. Salimi, N.; Rezaei, J. Evaluating firms' R\&D performance using best worst method. Eval. Progr. Plan. 2018, 66, 147-155.

46. Zhao, H.; Guo, S.; Zhao, H. Comprehensive benefit evaluation of eco-industrial parks by employing the best-worst method based on circular economy and sustainability. Environ. Dev. Sustain. 2017, 1-25. [CrossRef]

47. Di Zio, S.; Maretti, M. Acceptability of energy sources using an integration of the Delphi method and the analytic hierarchy process. Qual. Quant. 2014, 48, 2973-2991. [CrossRef]

48. Chang, I.S.; Tsujimura, Y.; Gen, M.; Tozawa, T. An efficient approach for large scale project planning based on fuzzy Delphi method. Fuzzy Sets Syst. 1995, 76, 277-288. [CrossRef]

49. Kuo, Y.F.; Chen, P.C. Constructing performance appraisal indicators for mobility of the service industries using Fuzzy Delphi Method. Expert Syst. Appl. 2008, 35, 1930-1939. [CrossRef]

50. Zhao, H.; Li, N. Evaluating the performance of thermal power enterprises using sustainability balanced scorecard, fuzzy Delphic and hybrid multi-criteria decision making approaches for sustainability. J. Clean. Prod. 2015, 108, 569-582. [CrossRef]

51. Jafari, A.; Jafarian, M.; Zareei, A.; Zaerpour, F. Using fuzzy Delphi method in maintenance strategy selection problem. J. Uncertain. Syst. 2008, 2, 289-298.

52. Shemshadi, A.; Shirazi, H.; Toreihi, M.; Tarokh, M.J. A fuzzy VIKOR method for supplier selection based on entropy measure for objective weighting. Expert Syst. Appl. 2011, 38, 12160-12167. [CrossRef] 
53. Liu, P.; Qin, X. An Extended VIKOR Method for Decision Making Problem with Interval-Valued Linguistic Intuitionistic Fuzzy Numbers Based on Entropy. Informatica 2017, 28, 665-685. [CrossRef]

54. Dong, J.; Yuan, F.; Wan, S. Extended VIKOR method for multiple criteria decision-making with linguistic hesitant fuzzy information. Comput. Ind. Eng. 2017, 112, 305-319. [CrossRef]

(c) 2018 by the authors. Licensee MDPI, Basel, Switzerland. This article is an open access article distributed under the terms and conditions of the Creative Commons Attribution (CC BY) license (http:/ / creativecommons.org/licenses/by/4.0/). 